\title{
Rhodium-BiPhePhos catalyzed hydroformylation studied by operando FTIR spectroscopy: Catalyst activation and rate determining step
}

\author{
Andreas Jörke $^{\mathrm{a}, *}$, Andreas Seidel-Morgenstern ${ }^{\mathrm{a}, \mathrm{b}}$, Christof Hamel ${ }^{\mathrm{a}, \mathrm{c}}$ \\ ${ }^{a}$ Otto von Guericke University, Institute of Process Engineering, Magdeburg, Germany \\ ${ }^{b}$ Max Planck Institute for Dynamics of Complex Technical Systems, Physical and Chemical Foundations of Process Engineering, Magdeburg, \\ Germany \\ ${ }^{c}$ Anhalt University of Applied Sciences, Department of Bioscience and Process Engineering, Köthen, Germany
}

\begin{abstract}
The homogeneously rhodium catalyzed hydroformylation of 1-decene was studied using operando FTIR spectroscopy. The bulky chelating diphosphite ligand BiPhePhos was used for catalyst modification. Special emphasis was given to the transformation of the Rh-precursor $\mathrm{Rh}(\mathrm{acac})(\mathrm{CO})_{2}$ to the activated $\mathrm{HRh}$ (BiPhePhos)(CO) 2 catalyst. Under hydroformylation conditions, this complex was found to be the most abundant catalyst species over a wide range of olefin conversion. Other inactive or non-selective rhodium species were not detectable. Analysis of the turnover frequency revealed a first order dependence of the hydroformylation rate with respect to the concentration of 1-decene. These findings indicate that the coordination of the olefin to the Rh-BiPhePhos catalyst is determining the hydroformylation rate of 1-decene.
\end{abstract}

Keywords: BiPhePhos, 1-decene, hydroformylation, rhodium

\section{Introduction}

The reaction of olefins with synthesis gas $\left(\mathrm{CO}, \mathrm{H}_{2}\right)$ in presence of a transition metal complex as catalyst has been known for decades as hydroformylation. It is one of the most important industrial applications of homogeneous catalysis [1]. The Rh-complex catalyzed hydroformylation of long-chain olefins using the bulky chelating diphosphite ligand BiPhePhos [2] was investigated intensively in the literature [3-6]. Usage of this catalyst enables the double bond isomerization of straight-chain olefins $[7,8]$ which can be exploited in tandem isomerization-hydroformylation reactions to produce linear aldehydes from mixtures of internal olefins [9-11] or renewable feedstocks $[12,13]$. However, desired mechanistic kinetic models of these reactions for efficient reactor design and operation are not available in the literature.

*Corresponding author, Tel.: +49-391-67-54655, Email: andreas.joerke@ovgu.de 
Mechanistic kinetic models of complex catalytic reaction cycles often include a large number of unknown kinetic parameters which are difficult to estimate [14]. Therefore, it is necessary to reduce these models to allow parameter estimation. Significant model reduction can be achieved by assuming one step in the catalytic reaction mechanism as rate determining step (RDS) [14]. A possibility to find out which step in a catalytic sequence is rate determining is the detection of intermediates. If one step is much slower than the others and therefore determining the rate, the intermediate before this step would accumulate as a consequence of Bodenstein's principle. In our case, most of the hydroformylation catalyst would therefore be present as Rh-carbonyl intermediate before a possible rate determining step.

Operando FTIR spectroscopy is a very useful tool to investigate homogeneously catalyzed reactions regarding the detection of reactants, intermediates and products [15, 16]. It is especially well suited for the detection and distinction of metal-carbonyls [17]. Therefore, this technique was applied in this contribution to the Rh-BiPhePhos catalyzed hydroformylation of 1-decene to undecanal to investigate which Rh-carbonyl species is the most abundant intermediate under reaction conditions and which step in the reaction mechanism can be regarded as rate determining. This information directly affects the mechanistic kinetic modeling of the mentioned reaction system, which is our goal in a subsequent publication. Furthermore, it is crucial to accurately balance the active, inactive or non-selective catalyst material present under reaction conditions for a correct description of the reaction rate and selectivities. Hence, the catalyst formation was also studied to evaluate, if possible inactive or non-selective Rh-complexes are formed from the Rh-precursor using BiPhePhos that do not take part in the desired hydroformylation reaction.

\section{Reaction mechanism}

A widely accepted hydroformylation reaction mechanism is the "Wilkinson cycle"[18] (See Figure 1 for chelating P-ligands including postulated catalyst pre-equilibrium). It is assumed in our case (1) that the oxidative hydrogen addition and the reductive elimination of the Rh-acyl complex VIII to release the aldehyde are irreversible [19-21] and (2) that under catalytic conditions the formation of non-selective unmodified Rh-tetracarbonyl complexes [22] and inactive Rh-dimers with bridging ligand is possible [3]. 


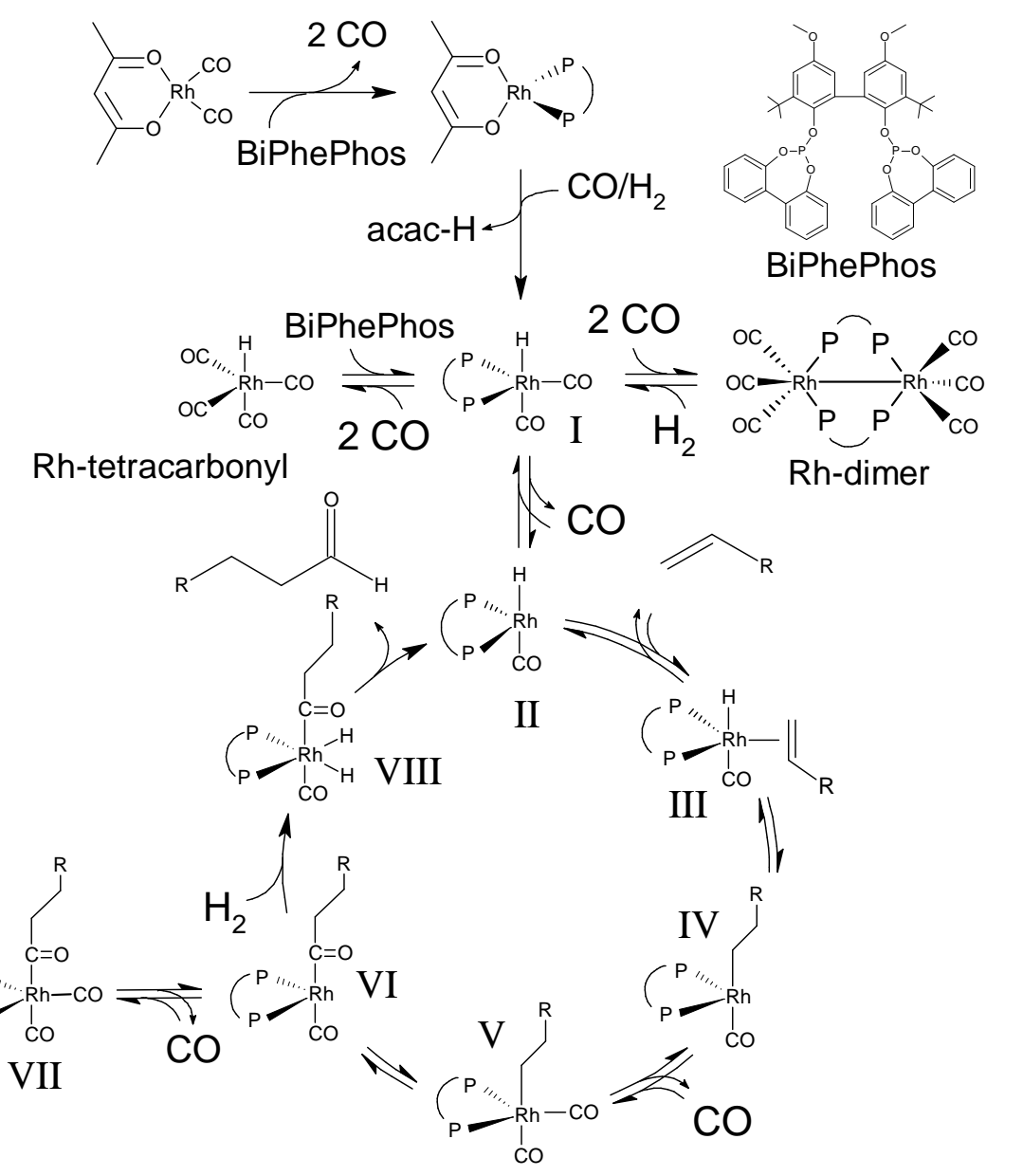

Figure 1: Rh-BiPhePhos catalyzed hydroformylation mechanism according to Evans and Wilkinson [18].

In the literature, mainly two possible RDS are discussed for the hydroformylation of cyclic, branched and straight-chain olefins: (1) the oxidative addition of hydrogen to the acyl complex VI which was observed for unmodified Rh-carbonyl complexes [19, 23, 24], monophosphines [25-28] and also monophosphites [20, 29] and (2) the coordination of the olefin double bond to the 16 valence electron (ve) Rh-hydridocarbonyl complex II which was also observed for monophosphines [30], diphosphines [31, 32], monophosphites [33-35] and diphosphites [36-38]. Two effects are responsible for the differing rate observations: (1) the ligand type ( $\sigma$-donor: phosphines, $\pi$-acceptor: phosphites) influences the electron density in the partially occupied d-orbitals of Rh which affects the $\pi$-backbonding ability of the metal with respect to substrates or $\mathrm{CO}$ ligands and (2) the steric interaction between substrate and ligand can slow down the coordination of the double bond to the metal center $[1,15,37]$. The coupling of both effects explains why the same catalyst shows different RDS with different substrates [20, 27]. Therefore, no general predictions regarding the RDS of a specific hydroformylation system can be made and experimental investigations are required. 


\section{Experimental}

To perform the operando FTIR studies, a $75 \mathrm{ml}$ autoclave (Parr Instrument Co.) was connected to an FTIR spectrometer (Mettler Toledo, ReactIR iC 10 with MCT detector cooled by liquid nitrogen, recorded wavenumber range $=700-2280 \mathrm{~cm}^{-1}$, wavenumber resolution $=8 \mathrm{~cm}^{-1}$ ) using a high pressure Si-ATR probe. The reactor was evacuated and flushed with nitrogen several times before toluene (Merck $99.9 \%$, used as received) was added with Schlenk technique through a capillary as solvent. After heating the solvent to $40{ }^{\circ} \mathrm{C}$ reaction temperature, the toluene background spectrum was recorded and removed. The Rh-precursor $\mathrm{Rh}(\mathrm{acac})(\mathrm{CO})_{2}$ (Umicore) and the ligand BiPhePhos (Molisa) were dissolved in toluene in separate Schlenk tubes, inertized and added to the reactor successively under constant stirring of 1200 rpm $($ Rh:Ligand = 1:1.5 (molar), Rh-concentration $=250 \mathrm{ppm})$. After pressurization of the reactor with 5 bar $\mathrm{H}_{2}$ and and subsequently 4 bar $\mathrm{CO}$ (total pressure $=9$ bar), the activation of the Rh-catalyst started. Afterwards, $28.3 \mathrm{mmol}$ of 1-decene (Sigma-Aldrich, $94.0 \%$, used as received) was added with Schlenk technique through a pressure lock with 10 bar $\mathrm{CO}$ against the 9 bar atmosphere in the reactor, causing the start of the hydroformylation reaction (final gas composition $\mathrm{CO}: \mathrm{H}_{2}=1: 1$, total pressure $=10$ bar, initial 1-decene concentration $=1.63 \mathrm{~mol} \mathrm{l}^{-1}$, Rh:Olefin $=1: 1000($ molar $)$ ). At low temperatures of $40{ }^{\circ} \mathrm{C}$, no significant double bond isomerization, hydrogenation or production of branched aldehydes could be detected with gas chromatography or FTIR spectroscopy (see discussion below). Hence, it was possible to study the hydroformylation reaction exclusively without the disturbing influence of side reactions.

\section{Results and discussion}

The experimentally observed operando FTIR spectra in the metal-carbonyl vibration region (1900 - 2200 $\mathrm{cm}^{-1}$ ) are shown in Figure 2 to Figure 3. The second derivative of the absorbance with respect to the wavenumber is used because it is almost insensitive to baseline shifts and allows better visual inspection of bands that correspond to highly diluted metal carbonyls. The catalyst pretreatment is presented in Figure 2 while Figure 3 shows the metal-carbonyl vibration region during hydroformylation until $75 \%$ conversion of 1-decene was reached (see Figure 8). Characteristic steady-state spectra were numbered in Figure 2 to Figure 3 and summarized in Figure 4. 


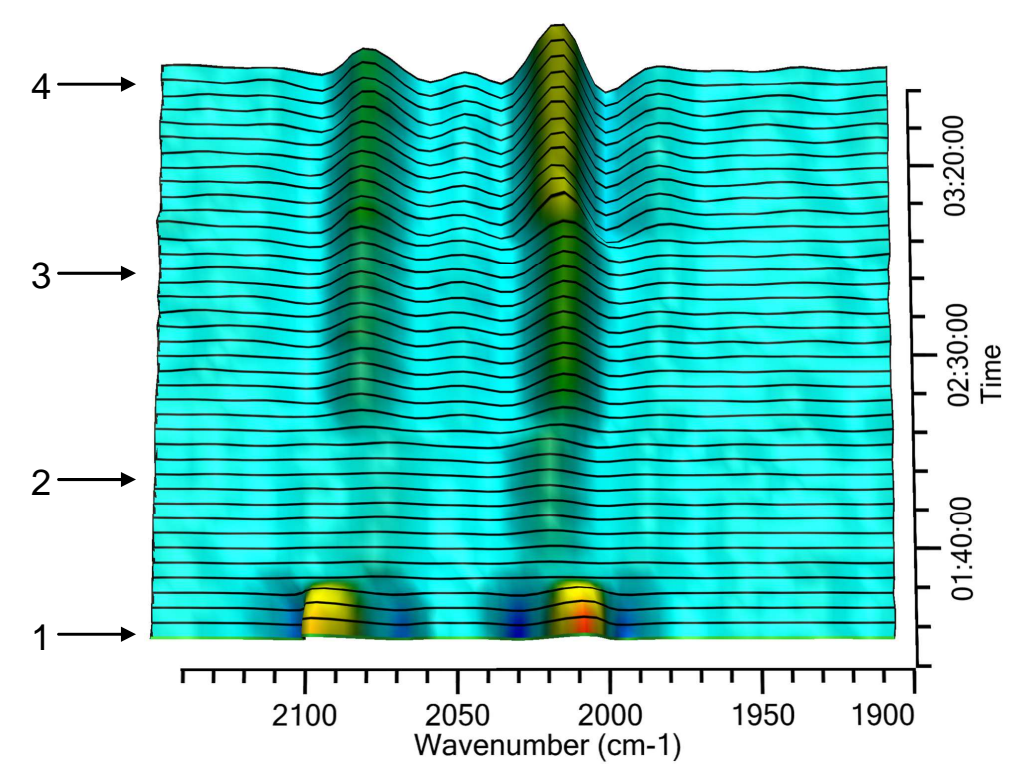

Figure 2: Operando FTIR spectra of the Rh-CO vibration region. Transformation of the Rh-precursor $\mathrm{Rh}(\mathrm{acac})(\mathrm{CO})_{2}$ to the activated Rh-hydridodicarbonyl complex I (Rh:Ligand $=1: 1.5$ (molar), $T=40^{\circ} \mathrm{C}$, solvent: toluene). Numbers indicate representative steadystate spectra summarized in Figure 4 . The 2nd derivative of the absorbance with respect to the wavenumber is shown to improve visual inspection.

After adding the Rh-precursor to the reactor, characteristic Rh-CO vibrations at $\alpha=2085 \mathrm{~cm}^{-1}$ and $\beta=2014$ $\mathrm{cm}^{-1}$ were observed (spectrum 1 ) in accordance to the literature [36, 39]. Adding the ligand causes the Rh$\mathrm{CO}$ vibrations to disappear rapidly, indicating an almost complete replacement of $\mathrm{CO}$ with BiPhePhos at the Rh-center (see Figure 1). A weakly intensive band remains at $\gamma=2025 \mathrm{~cm}^{-1}$ which could be assigned to a complex where the diphosphite is coordinated with one P-atom and one $\mathrm{CO}$ molecule remains at the Rh-center (spectrum 2) [36]. After adding 5 bar $\mathrm{H}_{2}$, the two characteristic Rh- $\mathrm{CO}$ vibrations of the Rh-hydridodicarbonyl complex I appear at $\delta=2077 \mathrm{~cm}^{-1}$ and $\epsilon=2017 \mathrm{~cm}^{-1}$ (spectrum 3), which is in accordance to the literature $[3,4,37]$. It was proven by independent DFT calculations that the observed Rh-CO vibrations for complex I correspond to an e,e-coordinated BiPhePhos ligand [4, 40]. This reaction is possible without adding additional $\mathrm{CO}$ because the $\mathrm{CO}$ that was replaced by BiPhePhos is most probably still dissolved in the solvent. Adding 4 bar $\mathrm{CO}$ increases the Rh-CO vibrations even further and complete conversion to complex I is reached instantly (spectra 4 and 5). No formation of other possibly inactive or non-selective Rh-species was observable. Therefore, the description of the catalyst pre-equilibrium can be simplified by neglecting the Rh-tetracarbonyl complex and the bridging Rh-dimer for the Rh-BiPhePhos system shown in Figure 1 under the applied reaction conditions. 


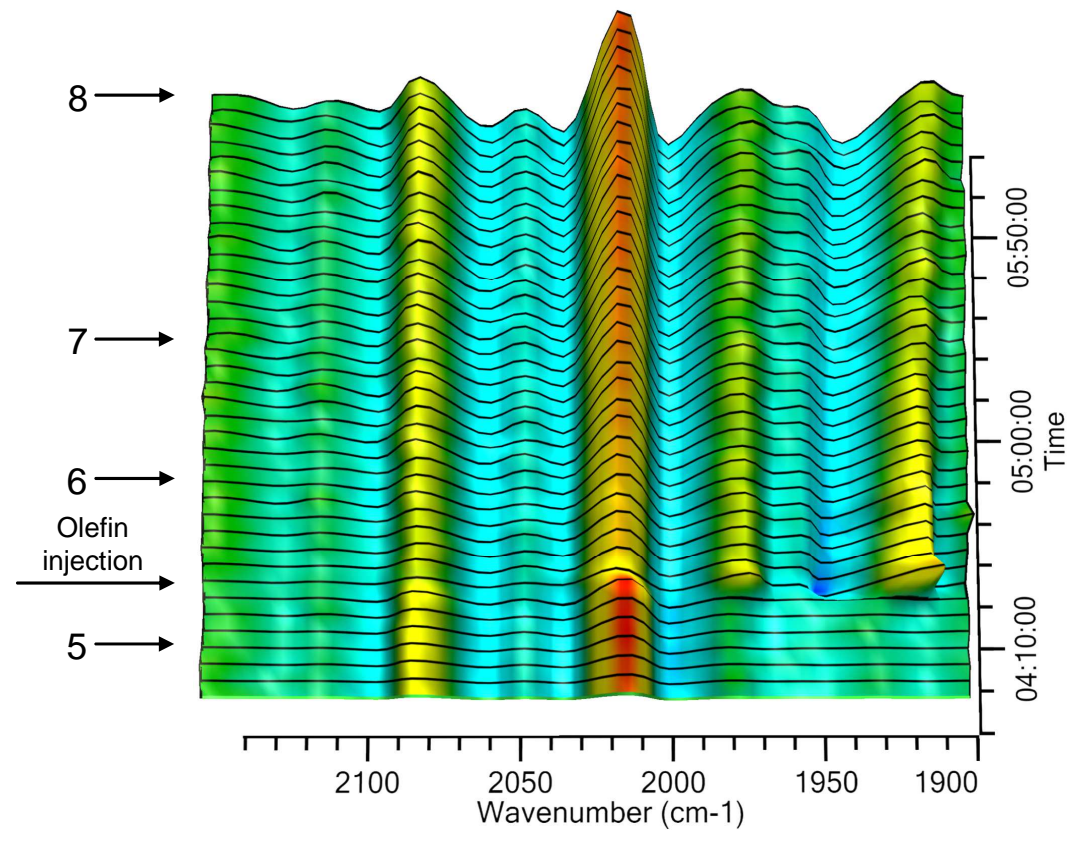

Figure 3: Operando FTIR spectra of the Rh-CO vibration region under hydroformylation conditions until $75 \%$ conversion of 1-decene (Rh:Ligand 1:1.5 (molar), Rh:Olefin $=1: 1000$ (molar), $p_{\mathrm{CO} / \mathrm{H}_{2}}=10 \mathrm{bar}, T=40^{\circ} \mathrm{C}$, solvent: toluene). Numbers indicate representative steady-state spectra summarized in Figure 4. The 2nd derivative of the absorbance with respect to the wavenumber is shown to improve visual inspection.

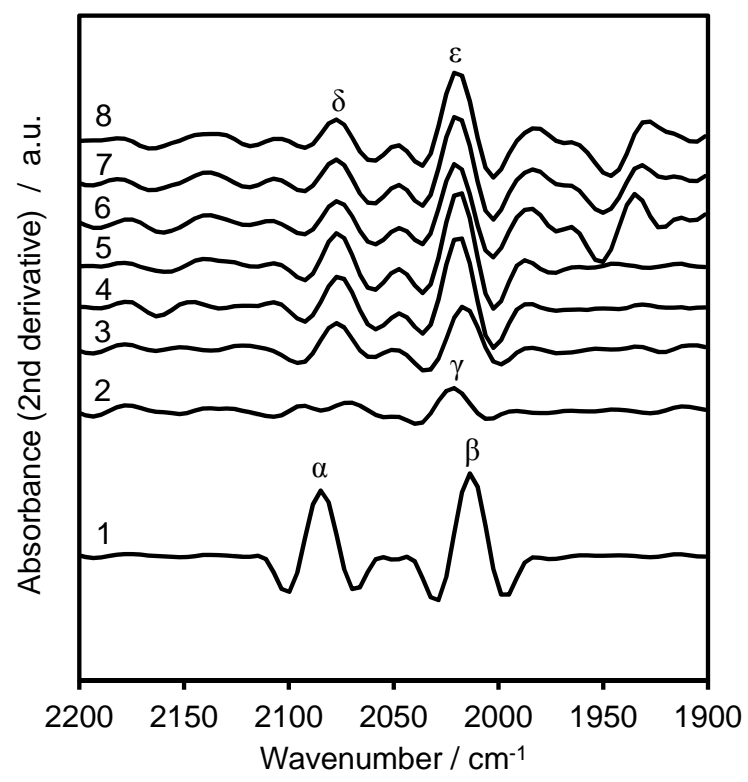

Figure 4: Selected operando FTIR spectra with characteristic Rh-CO bands $\left(\alpha=2085 \mathrm{~cm}^{-1}, \beta=2014 \mathrm{~cm}^{-1}, \gamma=2025 \mathrm{~cm}^{-1}, \delta=\right.$ $2077 \mathrm{~cm}^{-1}$ and $\epsilon=2017 \mathrm{~cm}^{-1}$ ). The 2 nd derivative of the absorbance with respect to the wavenumber is shown to improve visual inspection.

The detected bands in the metal-carbonyl region remain constant from the moment of olefin injection until $75 \%$ olefin conversion (see Figure 3). No wavenumber shift of the Rh-CO bands was observed (see Figure 4 , 
spectra 6-8). The slight intensity decrease is caused by a dilution due to the olefin injection. The mainly observed Rh-hydridodicarbonyl complex I is outside the catalytic cycle but at equilibrium with the active Rh-hydridocarbonyl complex II which is the starting point of the catalytic cycle and the Rh-intermediate before olefin coordination. Observing complex II is difficult because the equilibrium between I and II is on the side of the saturated 18ve complex I. Moreover, the Rh-CO vibration of the unsaturated 16ve complex II will be shifted only slightly compared to complex I which is probably within the wavenumber resolution of the IR spectrometer.

Possible catalyst or ligand degradation by oxidation during hydroformylation was rejected because the reaction temperature was low, the reaction solution was clear with a light green color and no particulates were observed after the experiment in the solution. Furthermore, the emergence of possible $\mathrm{P}=\mathrm{O}$ bands of oxidized phosphorus could not be detected in the typical $\mathrm{P}=\mathrm{O}$ wavenumber region of $1100-1300 \mathrm{~cm}^{-1}$ (see Figure 5).

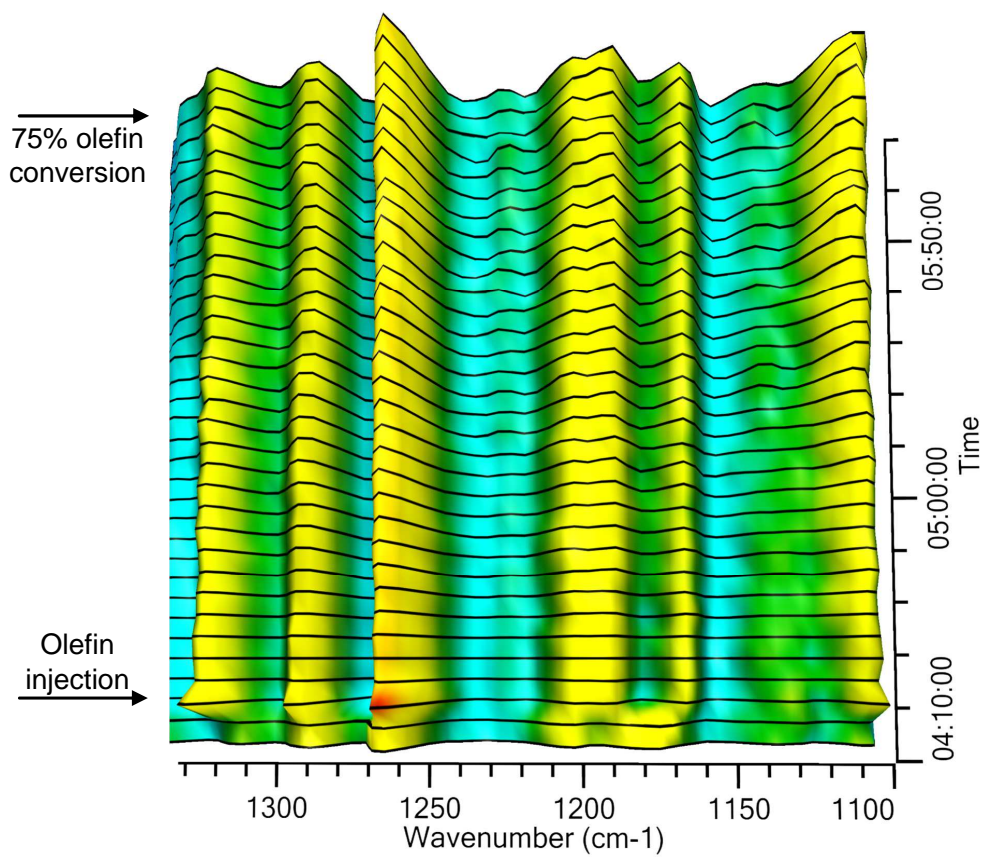

Figure 5: Operando FTIR spectra of the $\mathrm{P}=\mathrm{O}$ vibration region of oxidized phosphorus under hydroformylation conditions until $75 \%$ conversion of 1-decene (Rh:Ligand $=1: 1.5$ (molar), $T=40^{\circ} \mathrm{C}$, solvent: toluene). The 2 nd derivative of the absorbance with respect to the wavenumber is shown to improve visual inspection.

Characteristic $=\mathrm{C}-\mathrm{H}$ bending vibrations of the terminal double bond of 1-decene at 913 and $996 \mathrm{~cm}^{-1}$ can be seen in Figure 6. Olefins with internal double bond in trans position have one characteristic $=\mathrm{C}-\mathrm{H}$ bending vibration at $970 \mathrm{~cm}^{-1}$. However, this band was not observable to a significant extent confirming that double bond isomerization plays a minor role under the applied experimental conditions. 
The branched aldehyde 2-methylundecanal has a characteristic $\mathrm{C}-\mathrm{H}$ bending vibration at $921 \mathrm{~cm}^{-1}$ that does not appear in the spectrum of the corresponding terminal aldehyde dodecanal [41]. Hence, it is likely that this is also the case for the hydroformylation products of 1-decene. However, a similar band could not be observed (see Figure 6). Gas chromatographic analysis confirmed the high aldehyde regioselectivity after $75 \%$ conversion of 1 -decene of $n /$ iso $\approx 99: 1$. Thus, the production of branched aldehydes is negligible under the applied experimental conditions supporting that the Rh-BiPhePhos catalyst was not damaged significantly.

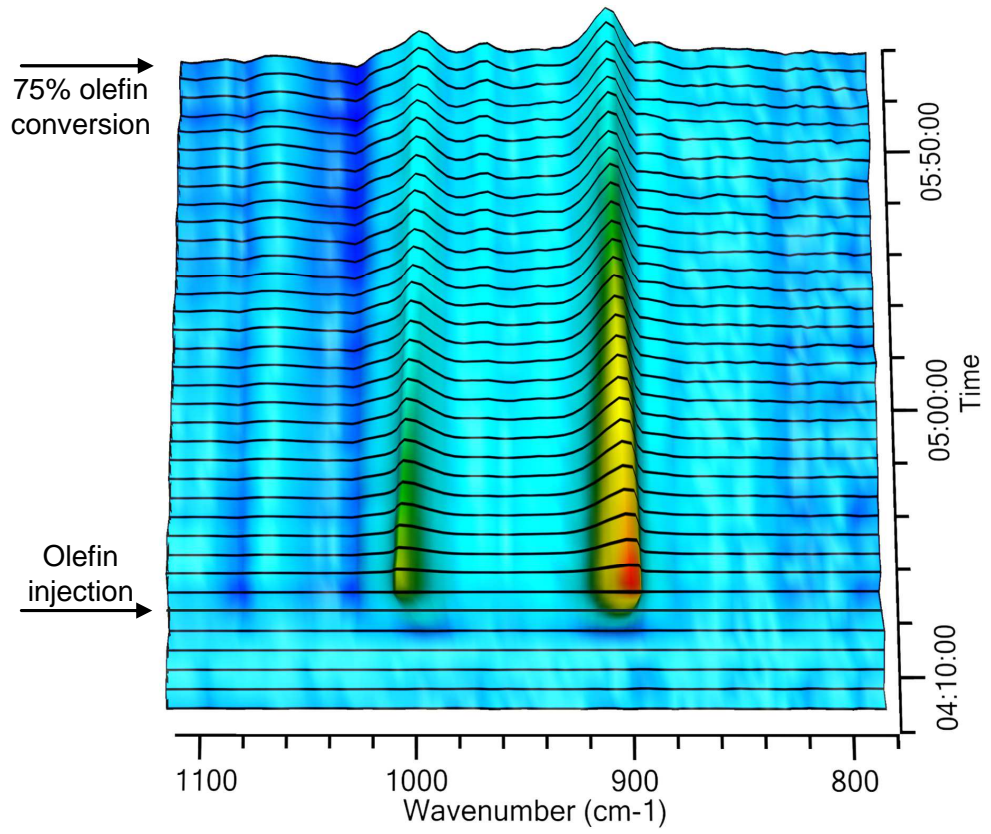

Figure 6: Operando FTIR spectra of the $=\mathrm{C}-\mathrm{H}$ bending vibration region under hydroformylation conditions until $75 \%$ conversion of 1-decene (Rh:Ligand $=1: 1.5$ (molar), $T=40^{\circ} \mathrm{C}$, solvent: toluene).

The strong $\mathrm{C}=\mathrm{O}$ stretching band of undecanal at $1729 \mathrm{~cm}^{-1}$ can be seen in Figure 7 as well as the less intensive $\mathrm{C}=\mathrm{C}$ stretching band of 1-decene at $1643 \mathrm{~cm}^{-1}$. Normalizing those bands in accordance to the stoichiometry of the hydroformylation reaction allowed to use them for the calculation of the conversion $X$ of 1-decene and the turnover frequency TOF (see Figure 8). 


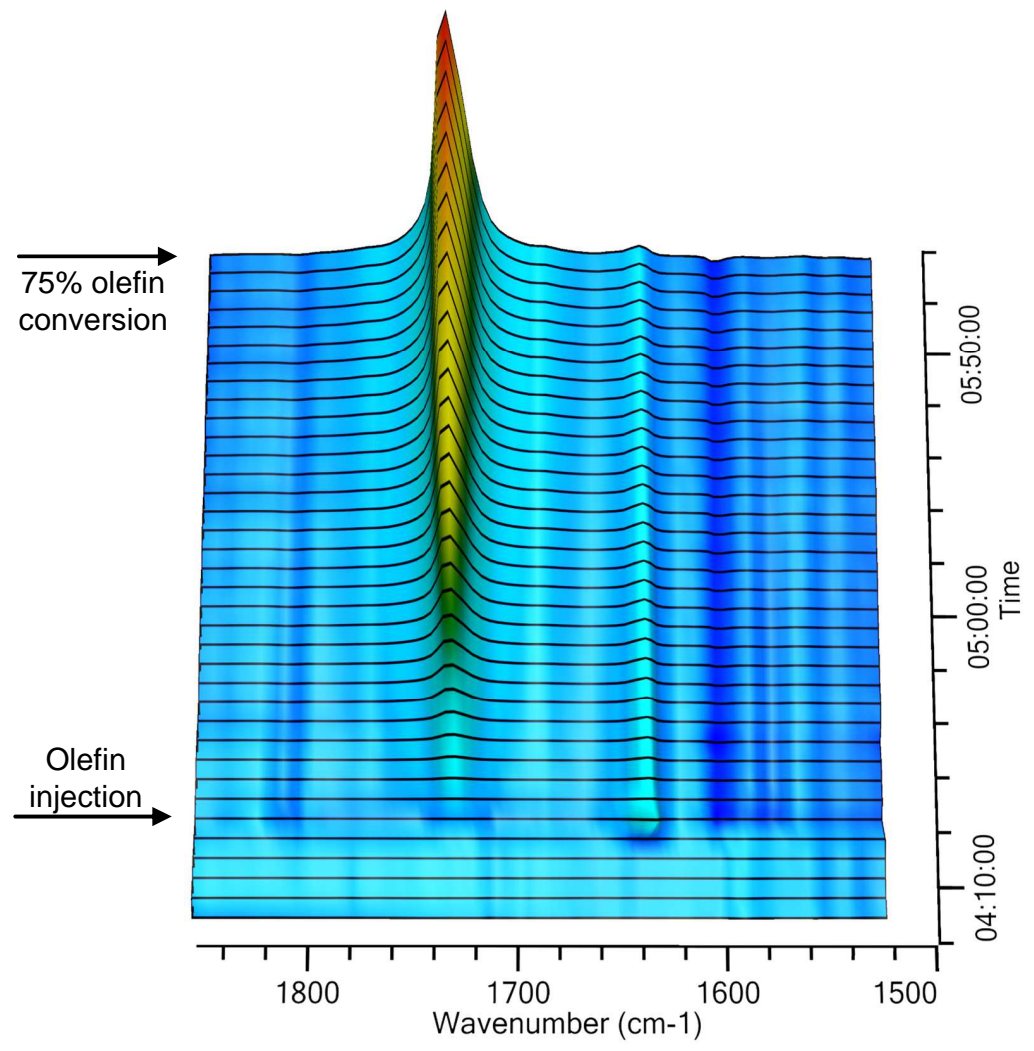

Figure 7: Operando FTIR spectra of the $\mathrm{C}=\mathrm{O}$ and $\mathrm{C}=\mathrm{C}$ stretching vibration region under hydroformylation conditions until $75 \%$ conversion of 1-decene (Rh:Ligand $=1: 1.5$ (molar), $T=40^{\circ} \mathrm{C}$, solvent: toluene).

The TOF is defined as the rate of aldehyde formation $r_{\text {ald }}$ divided by the total Rh concentration (1). The aldehyde production rate was calculated by finite differences (2) and the conversion $X$ of 1-decene (3).

$$
\begin{aligned}
\text { TOF } & =\frac{r_{\text {ald }}(t)}{c_{\mathrm{Rh}, \text { total }}} \\
r_{\text {ald }} & =\frac{\mathrm{d} c_{\text {ald }}}{\mathrm{d} t} \approx \frac{\Delta c_{\text {ald }}}{\Delta t} \\
c_{\text {ald }} & =X \cdot c_{1-\text { decene }}(t=0)
\end{aligned}
$$

It can be seen in Figure 8 that the TOF decreases from $800 \mathrm{~h}^{-1}$ to $200 \mathrm{~h}^{-1}$ for the studied system with ongoing reaction time. To check the relation between the concentration of 1-decene and the TOF, the latter is plotted in Figure 9 against $(1-X)$ which is equal to the substrate concentration divided by its initial value (normalized substrate concentration). 


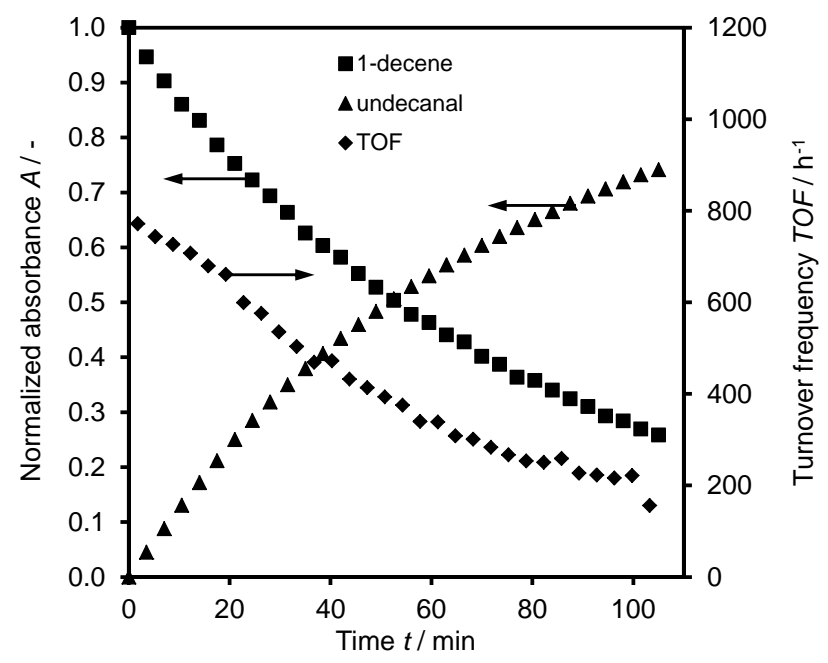

Figure 8: Normalized FTIR absorbance of the substrate 1-decene $\left(C=C\right.$ stretching vibration at $\left.1643 \mathrm{~cm}^{-1}\right)$ and the hydroformylation product undecanal $\left(\mathrm{C}=\mathrm{O}\right.$ stretching vibration at $\left.1729 \mathrm{~cm}^{-1}\right)$ as a function of reaction time with corresponding time resolved turnover frequency $T O F$.

The regression in Figure 9 shows a strong linear correlation $\left(R^{2}=0.9923\right)$ between the normalized concentration of 1-decene and the TOF. Hence, the hydroformylation is a first-order reaction with respect to the substrate concentration. Combining this finding with the operando FTIR results leads to the conclusion that the olefin coordination to the Rh-catalyst is most probably the rate determining step in the Rh-BiPhePhos catalyzed hydroformylation of 1-decene.

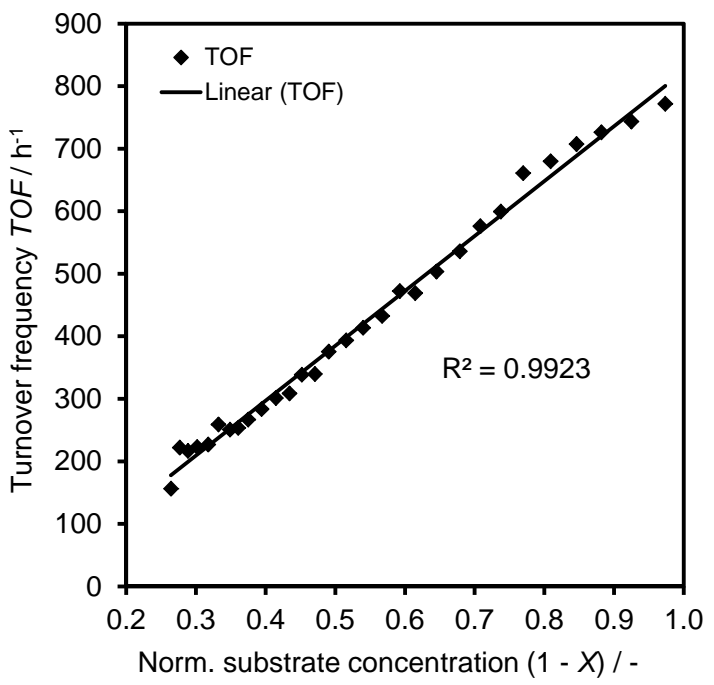

Figure 9: Turnover frequency TOF vs. normalized substrate concentration $(1-X)$. 


\section{Summary}

In summary, operando FTIR spectroscopy was successfully applied to study mechanistic features of the Rh-BiPhePhos catalyzed hydroformylation of 1-decene. The presented methodical approach was able to show experimentally that the transformation of the Rh-precursor $\mathrm{Rh}(\mathrm{acac})(\mathrm{CO})_{2}$ to the activated Rh-hydridodicarbonyl complex I proceeds fast, and that the diphosphite ligand BiPhePhos is coordinated in e,e-position at the Rh-center. It was not possible to detect any other inactive or non-selective Rh-complexes after catalyst activation and during hydroformylation which simplifies the description of the catalyst pre-equilibrium drastically. Under hydroformylation conditions, complex I was detected to be the most abundant Rh-intermediate over a wide range of olefin conversion. Possible catalyst or ligand degradation by oxidation during hydroformylation was rejected because no characteristic $\mathrm{P}=\mathrm{O}$ bands for oxidized phosphorus or particulates in the reaction solution were found. Analysis of the TOF revealed that the hydroformylation is of first order with respect to 1-decene. It was concluded that the olefin coordination is the rate determining step of the Rh-BiPhePhos catalyzed hydroformylation of 1-decene.

\section{Acknowledgment}

The financial support of the German Science Foundation (Project SFB/TRR 63: „InPROMPT - Integrated Chemical Processes in Multi-Phase Fluid Systems“) is gratefully acknowledged. We are also very grateful to Umicore AG and Co. KG for the supply of the catalyst precursor $\mathrm{Rh}(\mathrm{acac})(\mathrm{CO})_{2}$. 


\section{References}

[1] R. Franke, D. Selent, A. Börner, Chem. Rev. 112 (11) (2012) 5675-5732.

[2] E. Billig, A. G. Abatjoglou, D. R. Bryant, US Patent 4668651 A (1987).

[3] B. Moasser, W. L. Gladfelter, D. C. Roe, Organometallics 14 (8) (1995) 3832-3838.

[4] C. Kubis, Ph.D. thesis, University Rostock (2012).

[5] G. Kiedorf, D. M. Hoang, A. Müller, A. Jörke, J. Markert, H. Arellano-Garcia, A. Seidel-Morgenstern, C. Hamel, Chem. Eng. Sci. 115 (2014) 31-48.

[6] A. Rost, Y. Brunsch, A. Behr, R. Schomäcker, Chem. Eng. Tech. 37 (6) (2014) 1055-1064.

[7] A. Jörke, S. Triemer, A. Seidel-Morgenstern, C. Hamel, Chem. Ing. Tech. 87 (6) (2015) 713-725.

[8] A. Jörke, E. Kohls, S. Triemer, A. Seidel-Morgenstern, C. Hamel, M. Stein, Chem. Eng. Process. Process Intensif. 102 (2016) 229237.

[9] A. Behr, D. Obst, C. Schulte, T. Schosser, J. Mol. Catal. A: Chem. 206 (1-2) (2003) 179-184.

[10] C. Vogl, E. Paetzold, C. Fischer, U. Kragl, J. Mol. Catal. A: Chem. 232 (1-2) (2005) 41-44.

[11] M. Vilches-Herrera, L. Domke, A. Börner, ACS Catal. 4 (6) (2014) 1706-1724.

[12] E. N. Frankel, Ann. N.Y. Acad. Sci. 214 (1) (1973) 79-93.

[13] A. Behr, D. Obst, A. Westfechtel, Eur. J. Lipid Sci. Technol. 107 (4) (2005) 213-219.

[14] F. G. Helfferich, Kinetics of multistep reactions, 2nd Edition, Elsevier, Amsterdam and Boston, 2004.

[15] A. Behr, P. Neubert, Applied homogeneous catalysis, Wiley-VCH, Weinheim, 2012.

[16] O. Diebolt, P. W. N. M. van Leeuwen, P. C. J. Kamer, ACS Catal. 2 (11) (2012) 2357-2370.

[17] P. S. Braterman, Metal carbonyl spectra, Academic Press, London and New York, 1975.

[18] D. Evans, J. A. Osborn, G. Wilkinson, J. Chem. Soc. A (1968) 3133-3142.

[19] M. Garland, P. Pino, Organometallics 10 (6) (1991) 1693-1704.

[20] A. van Rooy, E. N. Orij, P. C. J. Kamer, P. W. N. M. van Leeuwen, Organometallics 14 (1) (1995) 34-43.

[21] R. Deshpande, J. Mol. Catal. A: Chem. 126 (2-3) (1997) 133-140.

[22] C. Li, E. Widjaja, W. Chew, M. Garland, Angew. Chem. Int. Ed. 41 (20) (2002) 3785-3789.

[23] C. Fyhr, M. Garland, Organometallics 12 (5) (1993) 1753-1764.

[24] J. Zhang, M. Poliakoff, M. W. George, Organometallics 22 (8) (2003) 1612-1618.

[25] B. M. Bhanage, S. S. Divekar, R. M. Deshpande, R. V. Chaudhari, J. Mol. Catal. A: Chem. 115 (2) (1997) 247-257.

[26] V. S. Nair, S. P. Mathew, R. V. Chaudhari, J. Mol. Catal. A: Chem. 143 (1-3) (1999) 99-110.

[27] M. Caporali, P. Frediani, A. Salvini, G. Laurenczy, Inorg. Chim. Acta 357 (15) (2004) 4537-4543.

[28] M. S. Shaharun, B. K. Dutta, H. Mukhtar, AIChE J. 55 (12) (2009) 3221-3233.

[29] C. Kubis, D. Selent, M. Sawall, R. Ludwig, K. Neymeyr, W. Baumann, R. Franke, A. Börner, Chemistry 18 (28) (2012) $8780-8794$.

[30] A. van Rooy, J. Organomet. Chem. 507 (1-2) (1996) 69-73.

[31] R. Bronger, J. P. Bermon, J. N. H. Reek, P. C. J. Kamer, P. W. N. M. van Leeuwen, D. N. Carter, P. Licence, M. Poliakoff, J. Mol. Catal. A: Chem. 224 (1-2) (2004) 145-152.

[32] E. Zuidema, L. Escorihuela, T. Eichelsheim, J. J. Carbó, C. Bo, P. C. J. Kamer, P. W. N. M. van Leeuwen, Chemistry 14 (6) (2008) 1843-1853.

[33] A. A. Dabbawala, H. C. Bajaj, R. V. Jasra, J. Mol. Catal. A: Chem. 302 (1-2) (2009) 97-106.

[34] M. S. Shaharun, B. K. Dutta, H. Mukhtar, S. Maitra, Chem. Eng. Sci. 65 (1) (2010) 273-281. 
[35] S. Güven, B. Hamers, R. Franke, M. Priske, M. Becker, D. Vogt, Catal. Sci. Technol. 4 (2) (2014) 524-530.

[36] A. van Rooy, P. C. J. Kamer, P. W. N. M. van Leeuwen, K. Goubitz, J. Fraanje, N. Veldman, A. L. Spek, Organometallics 15 (2) (1996) 835-847.

[37] P. W. N. M. van Leeuwen, P. C. J. Kamer, J. N. H. Reek, P. Dierkes, Chem. Rev. 100 (8) (2000) 2741-2770.

[38] S. N. Rush, Y. G. Noskov, T. E. Kron, G. A. Korneeva, Kinet. Catal. 50 (4) (2009) 557-566.

[39] R. van Eldik, S. Aygen, H. Kelm, A. M. Trzeciak, J. J. Ziólkowksi, Transition Met. Chem. 10 (1985) 167-171.

[40] D. Selent, R. Franke, C. Kubis, A. Spannenberg, W. Baumann, B. Kreidler, A. Börner, Organometallics 30 (17) (2011) $4509-4514$.

[41] NIST Mass Spec Data Center, Infrared spectra, in: P. Lindstrom, W. Mallard (Eds.), NIST Chemistry WebBook, NIST Standard Reference Database Number 69, National Institute of Standards and Technology, Gaithersburg, 2016. 